\title{
Migração, contato dialetal e o estabelecimento da variedade urbana de Imperatriz (MA)
}

\author{
Migration, dialect contact and the establishment of the urban variety of Imperatriz \\ (MA)
}

\author{
Orleane Evangelista de Santana* \\ Christina Abreu Gomes ${ }^{* *}$
}

\begin{abstract}
RESUMO: Este artigo apresenta os resultados de variáveis sociais do estudo de duas variáveis linguísticas, com dados de falantes da cidade de Imperatriz (MA), com o objetivo de identificar a consolidação dessa variedade urbana com passado rural recente. A variedade de Imperatriz é resultante de um processo de contato induzido (TRUDGILL, 1986; BRITAIN; TRUDGILL, 1999), devido à migração de falantes de diversas variedades regionais do Português Brasileiro, associado a um crescimento urbano acelerado. A estratificação da amostra por idade buscou mapear os sucessivos ciclos econômicos da cidade, o que permite situar a aquisição da variedade local em relação aos diferentes períodos de ocupação populacional, indo do período de maior isolamento como comunidade rural até os de intensa migração. O resultado de tempo aparente aponta, entre os falantes mais jovens, que adquiriram a variedade local no período de intensa urbanização, decréscimo no uso de variantes associadas à fala rural, aumento de variantes prestigiadas em

ABSTRACT: This paper presents the results of social variables of a study about two linguistic variables, with data from speakers from the city of Imperatriz (MA) in order to identify the strengthening of this urban variety with a recent rural past. The variety of Imperatriz is the outcome of a contact-induced process (TRUDGILL, 1986; BRITAIN; TRUDGILL, 1999), due to the intense migration of speakers from several regional varieties of Brazilian Portuguese, associated to an accelerated urban growth. The stratification of the speech sample by age sought to identify the speakers according the successive economic cycles of the city, which allows for the association of the acquisition of the local variety to different migratory waves going from the period of greater isolation as a rural community until periods with intense migration. The results for apparent time show that, among the younger speakers, who acquired the local variety in the period of intense urbanization, a decrease in the use of variants associated to rural speech, and the increase of prestige variants found in
\end{abstract}

Doutora em Linguística, Professora da Universidade Estadual do Maranhão (UEMASUL). https://orcid.org/0000-0002-2216-460X orleanesantana@bol.com.br.

** Doutora em Linguística, Professora Titular do Departamento de Linguística da UFRJ. https://orcid.org/0000-0003-0358-2029, christina-gomes@uol.com.br. 
grandes cidades, como a prevalência de formas verbais marcadas de $3^{\underline{a}}$ pessoa do plural com sujeito de $3^{\mathbf{a}}$ do plural sobre as formas não marcadas, a diminuição da semivogal, como em ['pariə] (palha), e o aumento da lateral seguida de semivogal, como em ['palı̃ ə]. São apresentadas evidências de que, em relação à implementação da consoante lateral, a direcionalidade da mudança também está relacionada à presença de um forte contingente de migrantes de diferentes regiões do Pará, que apresentam baixa ocorrência da semivogal.

PALAVRAS-CHAVE: Contato Dialetal. Migração. Variedade urbana. Fala Rural. Português Brasileiro. large cities, such as the prevalence of the marked forms of $3^{\text {rd }}$ plural person for $3^{\text {rd }}$ plural subjects over the unmarked forms, and the decrease of the semivowel, as in ['pario] (palha), and the increase of the lateral followed by a semivowel, as in ['palı⿰冫] ('straw'). We present evidence that, in the implementation of the lateral, the directionality of the change is due to the intense urbanization and also to the presence of a strong contingent from different regions of the state of Pará, which presents low rates of the semivowel.

KEYWORDS: Dialect Contact. Migration. Urban variety. Rural speech. Brazilian Portuguese.

\section{Introdução}

O presente artigo apresenta os resultados de um estudo realizado com falantes da cidade de Imperatriz, no Maranhão, com o objetivo de identificar a consolidação de uma variedade urbana, capturada na formação populacional da cidade (SANTANA, 2014) ${ }^{1}$. Originalmente uma localidade isolada com características rurais, localizada na fronteira do Bioma Amazônico, no Sudoeste do Estado do Maranhão (Anexo A), a partir dos anos 1960, teve um crescimento muito rápido com a chegada de um grande número de migrantes de diferentes estados do Brasil, sobretudo, principalmente, de migrantes oriundos de diferentes áreas do sertão maranhense. Os sucessivos movimentos migratórios, motivados pela conjuntura econômica, possibilitaram o contato de falantes de diversas regiões do Brasil, constituindo a base da formação dessa variedade linguística. Assim, tomando como base a formação de uma variedade a partir do contato de falantes de variedades mutuamente inteligíveis, e considerando

\footnotetext{
${ }^{1}$ Esse artigo se baseia em alguns dos resultados do capítulo 5 de Santana (2014).
} 
a origem rural recente da localidade e o processo rápido de urbanização, este artigo focaliza emergência de uma variedade urbana do Português Brasileiro (PB).

O comportamento dos falantes de Imperatriz foi observado em relação a duas variáveis linguísticas, cujas variantes estigmatizadas são associadas à fala rural (BORTONI-RICARDO, 1985), a saber: alternância entre consoante lateral e semivogal, como em mulher - mulié2, e alternância na marca flexional de verbos com sujeitos de $3^{\underline{a}}$ pessoa de plural, como em eles foram - eles foi, em função das variáveis sociais estratificadoras da Amostra de Imperatriz: idade, sexo e escolaridade. Essas variáveis linguísticas foram escolhidas porque as diferenças de frequência das variantes de cada uma das variáveis mencionadas, respectivamente, em especial, o percentual geral de ocorrência da semivogal e da realização de formas verbais não marcadas com sujeitos de $3^{\underline{a}}$ pessoa do plural, são indicativas de características de uma variedade urbana, ou rural, ou com influência de uma sobre a outra, dependendo do movimento populacional. A predominância da ausência de concordância e da semivogal no lugar da lateral palatal tem sido observada em estudos com população rural e pequenos centros urbanos, embora também seja expressiva em alguns centros urbanos de grande porte, conforme será apresentado na seção 2.

A amostra de fala para este estudo foi constituída com o objetivo de capturar as diferentes fases de formação e urbanização da cidade de Imperatriz em relação à ocupação humana e assim observar as consequências sociolinguísticas da transformação social e econômica da localidade.

Os pressupostos teóricos e procedimentos metodológicos de coleta e análise dos dados são os utilizados nos estudos de Variação e Mudança da Sociolinguística Variacionista (LABOV, 1972, 1994, 2001). Parte-se da hipótese de que o contato linguístico, de qualquer natureza, pode levar à mudança linguística (SANKOFF, 2002).

\footnotetext{
${ }^{2} \mathrm{~A}$ análise das variáveis sociais considerou a realização da semivogal em relação às outras duas variantes, uma vez que a variante com a semivogal é considerada característica de variedade rural.
} 
Também, segundo Williams e Kerswill (1999) e Kerswill e Williams (2000, 2005), a mistura dialetal, provocada pelo contato entre falantes de variedades mutuamente inteligíveis de uma mesma língua, leva à mudança. Essa situação foi denominada por Trudgill (1986) como contato dialetal. Com relação à formação de uma variedade a partir do contato de variedades mutuamente inteligíveis, Trudgill (1986, p. 127) e Britain e Trudgill (1999, p. 246-247) mencionam os processos de nivelamento, que envolvem a perda de variantes marcadas e demograficamente minoritárias; simplificação, situação em que formas minoritárias podem ser mantidas por serem mais simples; e realocação, situação em que duas ou mais variantes de variedades em contato sobrevivem ao nivelamento, passando a constituir uma variável linguística e a exercer novas funções sociais na variedade em desenvolvimento.

A mobilidade populacional no Brasil normalmente está relacionada a motivações econômicas, relacionadas à busca de condições de inserção no mercado de trabalho ou à busca de oportunidades de expansão econômica, por exemplo; respectivamente, nas migrações de população rural para área urbana, ou de ocupação de áreas territoriais com baixa densidade demográfica e perfil rural, como ainda acontece no Brasil em alguns estados das regiões Centro-Oeste, Nordeste e Norte. Segundo Bortoni-Ricardo $(1985,2010)$, a urbanização de dialetos rurais é o cerne dos processos de mudança e padronização linguísticas no Brasil, devendo ser entendida no contexto de um país em desenvolvimento. Portanto, no contexto específico de urbanização de uma variedade rural, como é o caso da cidade de Imperatriz, com um passado rural recente e que se tornou polo econômico e educacional para diversas localidades dos estados do Pará, Piauí e Tocantins, o esperado é que a mudança se dê na direção da consolidação de características de outras variedades urbanas constituídas há mais tempo, podendo incorporar características de variedade linguística com presença de um grande contingente de falantes. 
As seções a seguir apresentam uma descrição da distribuição das duas variáveis linguísticas anteriormente mencionadas a partir de estudos sobre o $\mathrm{PB}$, com a finalidade de identificar se há um continuum rural-urbano na distribuição das variantes, nos termos de Lucchesi et al. (2009, p. 348), seguida de uma breve apresentação da formação sócio-histórica da cidade, das hipóteses e da metodologia de pesquisa, dos resultados e das conclusões.

\section{As variáveis estudadas no continuum rural - urbano do PB}

Após mais de 30 anos de estudos sociolinguísticos no Brasil, o continuum ruralurbano do Português Brasileiro pode ser traçado a partir dos resultados obtidos sobre diferentes comunidades de fala, sendo estas eminentemente urbanas ou rurais, uma vez que a maior parte dos trabalhos de variação e mudança se concentra na descrição de variáveis que caracterizam falantes nativos das variedades estudadas. Por outro lado, poucos trabalhos incluíram a dinâmica do contato dialetal como parte do continuum rural-urbano, sendo o principal trabalho desenvolvido por Bortoni-Ricardo (1985). A sistematização da distribuição das variantes das duas variáveis sociolinguísticas, a partir da seleção de alguns trabalhos sobre diferentes variedades urbanas ou rurais do PB, tem por objetivo nortear a análise dos resultados obtidos para os dados de Imperatriz.

Com relação à concordância verbal de $3^{a}$ pessoa, Lucchesi et al. $(2009$, p. 348) mencionam um continuum rural-urbano que indica um quadro de polarização entre variedades rurais e urbanas associadas a níveis de escolaridade e situação socioeconômica. Assim, de acordo com os autores, o continuum se organiza na seguinte ordem, da menor para a maior taxa de realização da concordância:

a) taxas mais baixas de realização da concordância em comunidades rurais afrobrasileiras da Bahia, em torno de 16\%. Segundo os autores, esta seria uma característica de comunidades rurais pobres, especificamente do Norte e Nordeste do Brasil, já que 
o estudo de Almeida (2005, apud LUCCHESI et al., 2009) mostrou uma taxa alta de concordância de 3ª do plural (81\%) na comunidade rural afro-brasileira de São Miguel dos Pretos, no Rio Grande do Sul, devido ao contato dos falantes com os de outras comunidades por causa de emprego, saúde e educação (LUCCHESI et al., 2009, p. 361);

b) realização de $38 \%$ de concordância em comunidades de pescadores não alfabetizados ou semiescolarizados do norte do estado do Rio de Janeiro, resultado encontrado no estudo de Vieira (1997);

c) realização de $48 \%$ de concordância em falantes não alfabetizados da cidade do Rio de Janeiro, da Amostra Mobral do estudo de Naro (1981);

d) realização de 73\% e 79\% de concordância, respectivamente, por indivíduos escolarizados das cidades do Rio de Janeiro e Florianópolis, dos estudos de Scherre e Naro (1997) ${ }^{3}$ e Monguilhott (2001);

e) realização semicategórica da concordância por falantes universitários da cidade do Rio de Janeiro (Amostra NURC), em torno de 94\%, do trabalho de Graciosa (1991).

Recentemente, Gomes, Melo e Barcellos (2016) mostraram que falantes socialmente excluídos da cidade do Rio de Janeiro, especificamente da Amostra EJLA, formada por adolescentes menores infratores, oriundos de favelas do Rio de Janeiro, apresentam taxas bem baixas de realização de formas verbais de $3^{\text {a }}$ pessoa do plural que os aproximam ao observado nas comunidades afrodescendentes do estudo de Lucchesi et al. (2009). O percentual baixo desse grupo urbano, 23\%, e o percentual alto da população rural de São Miguel dos Pretos (RS), 81\%, indicam que o nível de escolaridade e o grau de integração social dos falantes podem ser preponderantes sobre a localidade (rural-urbano).

\footnotetext{
${ }^{3}$ Em estudo mais recente, Scherre e Naro (2010) mostram que o percentual geral de concordância em amostra mais recente da comunidade de fala do Rio de Janeiro, Censo 2000, é de 83\%.
} 
Já os estudos sobre a alternância de consoante lateral e semivogal não indicam exatamente uma polarização urbano-rural entre as duas variantes, uma vez que o continuum rural-urbano e o nível de escolaridade não são suficientes para dar conta da distribuição dos percentuais conhecidos de ocorrência da semivogal para diferentes comunidades de fala ${ }^{4}$, que se distribuem de forma descontínua, embora, a depender da região do país, as taxas mais altas da semivogal ocorram em pequenos centros urbanos do interior, conforme se observa nos estudos a seguir:

a) percentuais altos de ocorrência da semivogal em comunidade quilombola do interior de Minas Gerais, 60\%, no estudo de Castro (2006), assim como nas cidades do Projeto Varsul, 70\%, com falantes com ensino de fundamental a superior, sendo os percentuais nas capitais Porto Alegre, Florianópolis e Curitiba, respectivamente, 64\%, $42,9 \%$ e $62,3 \%$, nos resultados obtidos por Ferreira (2011).

b) percentuais baixos de ocorrência da semivogal em Belo Horizonte, 14\%, no estudo de Madureira (1997), e 19\%, no estudo de Pinheiro (2009); 19\%, em Papagaios (MG), região metropolitana de Belo Horizonte, falantes com ensino fundamental, médio e superior do estudo de Santos (2012); 16,8\% em Jacaúba, Paraíba, no estudo de Freire (2011), com falantes não alfabetizados e com até 8 anos de escolaridade; 18\% e $12 \%$, para falantes com menos ou mais de 8 anos de escolaridade, respectivamente, das cidades de Altamira e Marabá, no Pará, do trabalho de Soares (2008).

c) percentuais muito baixos da semivogal, caracterizando ocorrência semicategórica e categórica da lateral, na região metropolitana do Rio de Janeiro (Nova Iguaçu e Copacabana), do estudo de Quandt (2014), 0,5\% na região Noroeste e 3,5\% no Norte do estado do Rio (BRANDÃO, 2007), assim como nas capitais do Nordeste, 2\%, com falantes do ensino fundamental e superior (OLIVEIRA; MOTA, 2007) ${ }^{5}$; nos dados

\footnotetext{
4 Segundo Melo (1981, p. 77), a descontinuidade de distribuição tem relação com os caminhos dos bandeirantes paulistas e posterior difusão nas movimentações populacionais no interior do Brasil.

${ }^{5}$ As autoras apresentam o percentual geral da semivogal nas capitais do Nordeste e mencionam a predominância da semivogal em Aracaju e Teresina e respectivos pesos relativos, 0,86 e 0,63.
} 
do Atlas Linguístico do Acre do estudo de Santos e Chaves (2012), essa ocorrência ocorre 6,4\% na região do Alto Acre, 3,6\% na região de Purus e 1\% em Rio Branco (CHAVES; MELO, 2009); e, finalmente, os percentuais registrados no trabalho de Soares (2008), para as cidades paraenses Belém, Soure, Bragança e Santarém, respectivamente, foram $8 \%, 4 \%, 3 \%$ e $2 \%$, e do estudo de Nunes (2006), Curionópolis, Itupiranga, Dom Eliseu e Tucuruí, respectivamente, com 7\%, 5\%, 1\% e 4\%.

Do exposto, verifica-se que as duas variáveis linguísticas não se distribuem da mesma maneira no continuum rural-urbano. A relação entre rural e urbano no PB foi tratada no trabalho seminal de Bortoni-Ricardo (1985), que estudou o processo de urbanização dos falantes de dialetos rurais como consequência de um êxodo em massa de zonas rurais para áreas urbanas. A pesquisadora observou o comportamento de moradores de Brazlândia, cidade-satélite de Brasília, cujas famílias migraram de zonas rurais do estado de Minas Gerais, denominados como rurbanos pela autora, em relação à alternância entre lateral palatal e semivogal, como em palha paia, filho fio; redução de ditongo crescente, como em pulícia puliça, gêmeo gemu; concordância variável de $3^{\underline{a}}$ pessoa do plural e de $1^{\underline{a}}$ pessoa do plural, como em eles foru $\sim$ foram $\sim$ foi e nós fomos $\sim$ nós foi. Essas variáveis foram analisadas por serem bons indicadores do processo de urbanização de variedades rurais no Brasil. Para Bortoni-Ricardo, as duas variáveis fonológicas são típicas de variedades rurais e rurbanas do português brasileiro e são descontínuas em relação ao continuum dialetal. Já a realização variável de verbos de $3^{a}$ do plural de sujeitos no plural seria gradual em relação ao continuum dialetal.

A autora mostrou uma nítida diferença entre a geração mais velha de migrantes e a de seus filhos, sobrinhos ou netos, que chegaram a Brazlândia ainda crianças. Enquanto os mais velhos ainda mostravam características típicas de sua origem dialetal rural, demonstradas pelos percentuais globais de ocorrência da variante semivogal, ausência de glide no ditongo e ausência de marca de $3^{\text {a }}$ e $1^{\underline{a}}$ pessoas do plural, os mais jovens demonstraram ter passado por um processo de reestruturação 
de suas gramáticas, aproximando-se do comportamento observado em falantes de origem urbana. A autora demonstrou também que o processo de urbanização apresentou tendências diferentes para homens e mulheres, dependente de seu grau de integração e urbanização na esfera pública, através do contato resultante de necessidades de trabalho para os homens, e, para as mulheres, em função de relações interpessoais com parentes e vizinhos, por permanecerem em casa, estavam, portanto, menos expostas à cultura dominante, e, portanto, à variedade urbana (BORTONIRICARDO, 1985, p. 241-242).

\section{Formação Sócio-histórica de Imperatriz}

A região onde se encontra a cidade de Imperatriz, na região sudeste do estado do Maranhão, foi colonizada tardiamente, já no final do século XVIII, período bastante posterior à ocupação das regiões litorâneas, em que há registro da presença de europeus desde o século XVI (FRANKLIN, 2005). Em 1862, a Vila Nova de Imperatriz se instala na região de Santa Teresa, sendo elevada à categoria de cidade em 1924 . Durante todo esse tempo, até o início dos anos 1960, a localidade se caracteriza por ser uma região com baixa densidade populacional (Anexo A, Quadro 1) e de atividade eminentemente rural.

A primeira leva migratória que se deslocou para Imperatriz, ainda uma comunidade rural, se deu na virada para o século $X X$, quando os irmãos Pimentéis descobriram o caucho nas matas do Sul do Pará, próximas à localidade. Houve o deslocamento de pessoas de todo o Brasil, principalmente de cidades do Maranhão, sobretudo da zona rural, e do restante do Nordeste. Assim, moradores de outras regiões, sobretudo do interior do Maranhão, seguem para a região, visando trabalhar nessa atividade eminentemente agrária e, portanto, em uma região rural, a qual permaneceu como a principal atividade da região por quase 20 anos. A segunda leva migratória que se deslocou para Imperatriz, que permanecia ainda como uma 
comunidade rural, ocorreu no começo da década de 1950, quando chegou à cidade um grande contingente de lavradores que migraram de outros estados do Nordeste em busca das terras devolutas da região. Plantaram, sobretudo, grandes extensões de arroz para comercialização, dando início a uma nova etapa econômica da região, o chamado ciclo do arroz, o qual perdurou até a metade dos anos 1970, conforme Franklin (2008). A terceira leva migratória para Imperatriz, a partir de 1960 até 1980, devido à construção da rodovia Belém-Brasília, foi predominantemente de pessoas de outras localidades maranhenses que fugiam da aridez do Sertão, e de pessoas dos estados limítrofes Piauí, Pará e Goiás, que, ao tomarem conhecimento da existência de uma grande área situada ao lado de um rio caudaloso, com muitas terras férteis e devolutas, com chuvas regulares, próxima ao garimpo de Serra Pelada (década de 1980) e, ainda, com uma rodovia recém-construída dando-lhe acesso, não mediram esforços para se deslocar rumo a essa região, que permanecia ainda isolada, e que passou a ser denominada como Sibéria maranhense (informação obtida em entrevista com um dos informantes da amostra). Essa terceira leva de migrantes provocou o aumento populacional e, em um contexto de atividades econômicas não mais exclusivamente agrárias, fez com que a região se desenvolvesse em uma área urbana com todas as demandas inerentes a essa modificação, como a criação de mais escolas, serviços etc. (FRANKLIN, 2008).

A partir do exposto, a formação sócio-histórica de Imperatriz pode ser dividida em dois momentos: antes e depois da construção da rodovia Belém-Brasília em 1960. Conforme pode ser visto no Anexo A (Quadro 1), no período anterior, a cidade possuía um pequeno contingente populacional com predominância da população rural (8.329 habitantes) sobre a urbana (1.002 habitantes) e, consequentemente, apresentando características e hábitos interioranos típicos de comunidade rural. A partir dos anos 1960, com a rodovia já construída e devido à sua localização geográfica estratégica, interligando três estados - Piauí, Pará e Goiás -, a cidade de Imperatriz recebeu um 
grande número de migrantes de outras cidades maranhenses e, também, de outros 24 estados do Brasil (Anexo A, Quadro 2), o que resultou em um rápido crescimento populacional e no contato de uma diversidade de variedades do PB, reunidas em uma mesma comunidade. Esse último surto populacional fez com que, em 20 anos, a população predominantemente rural passasse a predominantemente urbana. Em todos os períodos verificados, através do Censo, destaca-se a predominância de migrantes do estado do Maranhão. De acordo com o Quadro 2, apresentado no Anexo A, também se observa que, em 1960, 1970 e 1980, migrantes oriundos do Piauí constituem o segundo grupo mais populoso, e, em 1991 e 2000, migrantes vindos da região do Pará. O quadro não permite identificar se houve um contingente numeroso de uma localidade específica de cada um desses estados. O mais provável é que o fluxo migratório para Imperatriz das diversas regiões brasileiras não concentre um conjunto significativo de falantes de uma mesma localidade. Do ponto de vista linguístico, isso significa que não houve nenhuma variedade preponderante em relação às demais.

Segundo Aguilera (2010, p. 72), as atividades açucareiras no Nordeste e a criação de gado, tanto no Nordeste quanto no Sul, fortaleceram a expansão territorial do país em dois grandes movimentos: do Sul em direção a Sorocaba-SP e a Minas Gerais; e, de Salvador - BA, em direção ao Nordeste até São Luís - MA, quando se formam centenas de cidades originárias de pousos dos tropeiros e do gado. Segundo os relatos históricos, a cidade de Imperatriz estava na rota dos Bandeirantes. Esses tropeiros transportavam diferentes variedades linguísticas ao longo de mais de quatrocentos anos, fazendo a história socioeconômica do Brasil e, ao mesmo tempo, fazendo a história do Português Brasileiro. Segundo Aguilera (2010, p. 86), “o papel mais importante coube aos Bandeirantes paulistas na expansão das fronteiras territoriais e linguísticas, levando um português popular e rural que ainda subsiste e pode ser comprovado, pelo menos, nos estados que já fizeram seu atlas linguístico". O relato de Aguilera reforça a evidência de que a área rural do Maranhão deveria conter 
algumas das características do que se conhece de outras áreas mapeadas do dialeto caipira, como as variáveis estudadas: ausência de concordância verbal de $3^{3}$ pessoa e da semivogal no lugar da lateral (AMARAL, 1976, p. 5-7) .

Do exposto, podemos inferir que o perfil rural de Imperatriz tem raízes nos Bandeirantes, que passaram pela localidade (mais antiga), e nas variedades de migrantes oriundos de outras localidades maranhenses e de outros estados, como Piauí e Bahia, que também estiveram na rota dos Bandeirantes. Assim, três momentos devem ser considerados na análise: uma origem rural recente, com poucos habitantes e com baixo fluxo migratório no ciclo do caucho (823 habitantes, da virada do século até 1923) e no ciclo do arroz (10.857 habitantes, década de 1950); a urbanização, com intenso fluxo migratório (220.095 habitantes, de 1960 a 1980), até a consolidação como polo econômico e educacional (247.505 habitantes, últimas três décadas). Considerando essas etapas de formação de Imperatriz, será observado o impacto dessas mudanças no perfil da localidade, de rural a urbana e, posteriormente, constituindo polo educacional recente na região, no que diz respeito à dinâmica sociolinguística dessa variedade do PB.

\section{Hipóteses e Metodologia}

Conforme mencionado na Introdução, o objetivo do estudo de Santana (2014) foi o de capturar a dinâmica da comunidade de fala em um contexto de transformação socioeconômica, a partir de um passado recente predominantemente rural, seguido de um rápido processo de crescimento populacional e de urbanização devido à intensa migração populacional, resultando no contato entre diferentes variedades do PB. Assim, considerou-se que a passagem de uma Imperatriz rural a urbana, provocada pela chegada de falantes de diversas origens dialetais e pelas mudanças econômicas, afetou a dinâmica linguística da variedade falada na localidade, com o aumento do contingente populacional de origem rural, vindo predominantemente do sertão 
maranhense. Em função disso, a hipótese é a de que tenha ocorrido uma mistura dialetal que, associada à transformação econômica da localidade, resultou em uma mudança no perfil linguístico da cidade em relação à variedade rural. Foi também objetivo da pesquisa detectar em que medida as características podem ser mais associadas a uma variedade urbana, considerando o continuum rural-urbano descrito na seção 2 .

A perspectiva teórica adotada é a da Sociolinguística Variacionista (LABOV, 1972, 1994, 2001), que postula que o conhecimento linguístico internalizado é dotado de heterogeneidade sistemática e que o indivíduo não é autônomo em relação à comunidade de fala. A variação observada na fala é, portanto, sistemática e pode estar relacionada a processo de mudança em curso. Para a realização do estudo, foi coletada, em 2012 e 2013, a amostra de Imperatriz, composta por 36 informantes, nascidos ou vindos para a localidade com no máximo quatro anos de idade, independentemente da origem regional e dialetal dos pais. Esse critério visou focalizar falantes cujo período de aquisição do PB correspondesse às diferentes fases econômicas pelas quais passou a cidade, determinando diferentes levas migratórias, conforme já mencionado e pode ser observado no Anexo A (Quadro 2). Os parâmetros estratificadores da amostra foram: faixa etária (14 a 20, 21 a 52 e acima de 53 anos), nível de escolaridade (Ensino Fundamental, Ensino Médio e Ensino Superior), e sexo (masculino e feminino). Os falantes dessa amostra estão distribuídos aleatoriamente por diferentes bairros da cidade.

As faixas etárias foram estabelecidas para capturar as fases de formação e urbanização da cidade de Imperatriz, em relação à ocupação humana e às transformações econômicas. Assim, as faixas etárias têm relação com os três diferentes momentos da história da cidade, conforme apresentados na seção 2, a saber: o isolamento, com predominância rural, até 1959 (falantes com 53 a 76 anos), o boom econômico com intensa migração, de 1960 a 1991 (falantes entre 21 e 52 anos de idade), 
e o período de consolidação como uma referência econômica e de educação para uma vasta região, a partir de 1992 (falantes entre 14 e 20 anos de idade). Os falantes mais velhos, nascidos até 1959, constituem o grupo exposto a uma variedade local isolada, sem ou com pouco contato com falantes de outras regiões. Os nascidos a partir de 1960 se inserem em um contexto de fluxo migratório crescente, associado a transformações econômicas da transição de área rural para centro urbano, culminando no contexto de cidade de grande porte para a região e consolidação como polo educacional para os nascidos a partir de 1992.

As entrevistas seguem os princípios metodológicos de Labov (1972), para que se aproximem ao máximo do vernáculo do falante, situação de uso em que o falante não monitora sua fala, e foram gravadas em gravador digital.

Para a realização deste estudo foram analisados os dados levantados de 18 dos 36 falantes que compõem a amostra, distribuídos de acordo com a estratificação por idade, sexo e escolaridade. São 6 falantes de cada Faixa etária/Ciclo econômico e migratório (53-75 anos/isolamento, com predominância rural, até 1959; 21-52 anos/boom econômico com intensa migração, 1960-1991; 14-20 anos/consolidação como polo econômico e educacional), sendo 2 de cada nível de escolaridade (fundamental, médio e superior), e 1 de cada sexo por célula (ver SANTANA, 2014, p. 79).

A seção a seguir apresenta os resultados para as duas variáveis linguísticas concordância verbal de $3^{\underline{a}}$ pessoa e alternância entre lateral e semivogal - em função das variáveis estratificadoras da amostra (faixa etária, sexo e escolaridade). A análise também inclui uma observação qualitativa dos dados e a observação do comportamento de alguns indivíduos para situar a perda de características de fala rural. 


\section{Resultados}

O perfil sociolinguístico da comunidade de fala de Imperatriz foi analisado em função da distribuição das variantes de cada variável linguística por faixa etária, escolaridade e sexo, conforme mencionado anteriormente, com o objetivo de identificar o atual perfil sociolinguístico da cidade de Imperatriz.

Os percentuais gerais obtidos para as aplicações de cada variável linguística foram: 22\% de semivogal (243/1094), como em mulié, e 36\% de ausência de concordância verbal (CV) de 3a pessoa (585/1586), como em Eles fala. Os percentuais gerais de cada variável indicam que, a princípio, houve uma tendência à perda de características linguísticas típicas de variedades rurais, características apontadas por Bortoni-Ricardo (1985) como típicas de zona rural, tais quais a semivogal e a ausência de CV de $3^{\underline{a}}$ pessoa do plural. Qual o grau de associação de cada uma das variantes com característica de variedade rural é um aspecto que precisa ser ainda explorado, uma vez que não há estudos que tenham abordado diretamente essa questão, considerando a percepção como indicadora de ruralidade e a avaliação ou o valor social que os falantes atribuem a elas. Pode-se especular no momento, tomando como base o que já se conhece sobre a realização dessas variantes nos diferentes estudos sobre elas em diversas variedades do PB, alguns citados anteriormente na seção 2, que a semivogal é mais fortemente associada à fala rural. Já a associação de formas verbais não marcadas de $3^{a}$ pessoa do singular com sujeitos marcados no plural à característica de ruralidade vai depender não só do percentual de ocorrência dessas formas, mas também da incidência com verbos considerados de nível mais alto de saliência fônica, nos termos de Naro (1981), como em Eles faz, Elas é, As pessoas veio.

Os dados de cada variável linguística foram submetidos à regressão logística, utilizando o pacote Goldvarb 2001, para verificar o efeito das variáveis sociais estratificadoras da amostra no condicionamento da variação, isto é, a significância estatística das variáveis idade, sexo e escolaridade. No Goldvarb, a significância 
estatística de uma variável explicativa é indicada através da ordem de seleção, no stepup das variáveis independentes com nível de significância abaixo de 0.05. Da mesma forma, se não há significância estatística, a variável não é selecionada. Além de indicar os grupos de fatores relevantes no condicionamento da variação, o Goldvarb também fornece, para cada fator de um grupo de fatores, o peso relativo, isto é, a probabilidade de aplicação ou ocorrência da variante em análise naquele determinado contexto (ou característica), seja linguístico ou extralinguístico. Os valores se distribuem em um intervalo ente 0 e 1 . Valores próximos de 0 indicam desfavorecimento e valores próximos de 1 indicam favorecimento da variante para o condicionamento avaliado para cada fator de uma variável explicativa. Na rodada relativa aos dados da semivogal, foram selecionadas, na seguinte ordem, as variáveis idade e escolaridade. Em relação aos dados da concordância verbal de $3^{a}$ do plural, foi selecionada somente a variável sexo. Serão apresentados a seguir os resultados obtidos das variantes de cada uma das variáveis linguísticas para as três variáveis sociais.

O Gráfico 1 a seguir mostra a distribuição da semivogal e da forma verbal não marcada de $3^{\underline{a}}$ pessoa com sujeito plural em função da faixa etária ${ }^{6}$.

Gráfico 1 - Distribuição da semivogal e da ausência de CV por faixa etária.

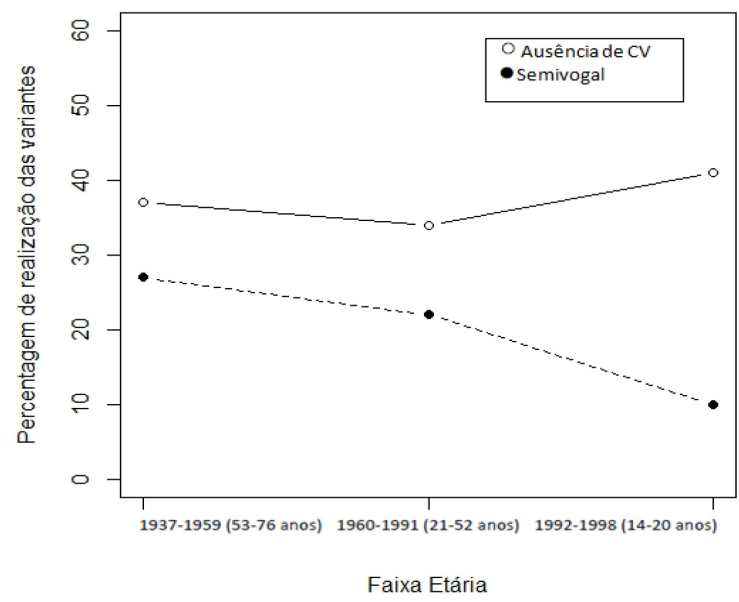

Fonte: Baseado em Santana (2014, p. 96).

\footnotetext{
${ }^{6}$ Optou-se por apresentar a ordenação de idade/data de nascimento dos mais velhos para os mais novos, como em diversos estudos da área (BAILEY, 2002, p. 313-323).
} 
Conforme pode ser observado, a distribuição das frequências das variantes pelas faixas etárias revelou, para a alternância entre consoante lateral e semivogal, uma frequência baixa de uso da variante semivogal nas três faixas de idade, com mais ocorrências entre os mais idosos (peso relativo $=0.623$ ) que os intermediários (peso relativo $=0.457)$, e frequência mais alta na faixa intermediária em relação aos mais novos da amostra, os adolescentes (peso relativo $=0.341$ ). Essa distribuição indica um perfil de mudança em progresso, no sentido da implementação da variante lateral, com maior frequência da lateral (alveolar ou palatalizada) seguida de semivogal, 76\%, como em mulié. Registre-se que a articulação palatalizada difere da articulação palatal $[K]$, com menos ocorrências. As percentagens de ausência de concordância indicam também uma predominância no uso de formas marcadas de $3^{\text {a }}$ pessoa do plural em todas as faixas etárias. Além disso, uma vez que não há diferença entre os mais velhos e os mais jovens, configura-se um perfil de variação estável. Conforme mencionado anteriormente, a variável idade não foi selecionada para os dados de concordância verbal. O resultado de tempo aparente indica tendência à redução drástica da semivogal, característica de fala rural, e estabilidade das variantes de concordância verbal.

O percentual global das variantes semivogal (22\%) e a ausência de marca de $3^{\text {a }}$ do plural (36\%) indicam que, no intervalo de 50 anos, as características mais marcantes de uma variedade rural teriam dado lugar a variantes de maior prestígio em áreas urbanas. O desvio padrão dos percentuais observados para as duas variantes foi, respectivamente, $21,35 \%$ e $12,92 \%$, o que indica que houve menor variabilidade entre

\footnotetext{
${ }^{7}$ Os percentuais obtidos por falante para realização da semivogal (sv) e ausência de CV de $3^{\text {a }}$ pessoa foram, por grupo etário: 53-76 anos: Dul -sv: 40\%, CV: 50\%, Sal - sv: 3\%, CV: 34\%, Lam - sv: 17\%, CV: 24\%, Ild - sv: 11\%, CV: 37\%, Chi - sv: 82\%, CV: 37\%, Ros -sv: 26\%, CV: 46\%; 21-52 anos: Ant - sv: 9,6\%, CV: 20\%, Val - sv: 3,5\%, CV: 19\%, Edn - sv: 2,5\%, CV: 40,4\%, Eun - sv: 3\%, CV: 36,3\%, Cil - sv: 52\%, CV: 49,2\%, Jos - sv: 27,4\%, CV: 27,6\%; 14-20 anos: Clé - sv: 15,7\%, CV: 65,9\%, Pau - sv: 28,5\%, CV: 39,4\%, Déb - sv: 2,7\%, CV: 30,9\%, Luc - sv: 30,7\%, CV: 42,8\%, Myl - sv: 0\%, CV: 20,7\%, Vin - sv: 8,3\%, CV: 56,5\% (SANTANA, 2014, p. 98-102).
} 
os falantes em relação à concordância verbal, isto é, estão mais próximos da média da comunidade de fala, e maior variabilidade entre os indivíduos da amostra na realização da variante semivogal. Há o caso em que o falante não produziu nenhum dado com a semivogal, assim como há o que produziu $82 \%$ de semivogal em alternância com as demais variantes.

Os percentuais comparados para as variantes das duas variáveis, em função da escolaridade e do sexo dos falantes, podem ser observados nos Gráficos 2 e 3 a seguir. A distribuição das variantes em relação a essas duas variáveis sociais traz informações sobre o valor social das variantes.

Gráfico 2 - Distribuição das variantes das duas variantes por escolaridade.

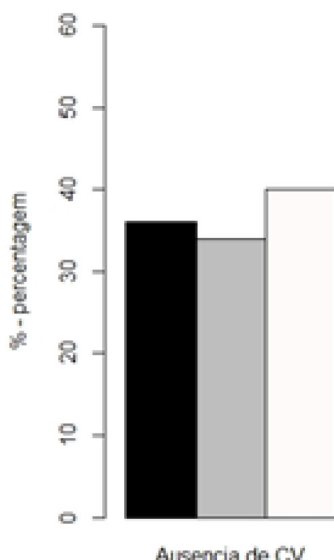

Ausencia de CV
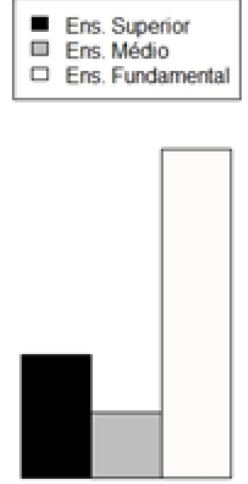

Semivogal
Gráfico 3 - Distribuição das duas variantes por sexo.
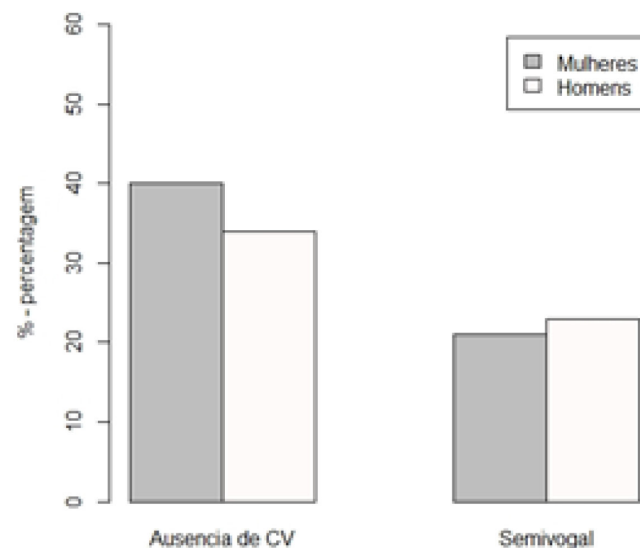

Semivogal

Fonte: Baseado em Santana (2014, p. 104, 106).

De acordo com o Gráfico 2, com relação à concordância verbal de $3^{\text {a }}$ pessoa do plural, não houve diferença significativa entre os percentuais obtidos para os três níveis de escolaridade, já indicado na não seleção dessa variável pelo Goldvarb, conforme mencionado anteriormente. Com relação à realização da semivogal, há uma diferença acentuada dos percentuais de ocorrência entre falantes com nível superior (peso relativo $=0.442)$ e médio (peso-relativo $=0.475)$ em relação aos falantes com ensino fundamental (peso relativo $=0.738$ ), sendo os percentuais de uso mais altos 
entre esses últimos. Esses resultados apontam para o efeito da variável escolaridade para essa variável linguística. Já a distribuição das variantes em função do sexo dos falantes, conforme o Gráfico 3, foi significativa somente para os dados da concordância verbal de 3a pessoa, único grupo de fatores selecionado pelo Goldvarb, sendo menos frequentes as formas não marcadas de $3^{a}$ pessoa entre os homens (peso relativo $=0,472$ ) e mais frequentes entre as mulheres (peso relativo $=0.536$ ).

Do exposto, observa-se que o perfil sociolinguístico da variedade falada na cidade de Imperatriz se caracteriza por apresentar incidência mais baixa de variantes que são típicas de áreas rurais. Os resultados para faixa etária indicam que existe uma tendência de mudança nessa direção para a alternância lateral e semivogal, ao passo que a alternância de formas verbais com sujeitos de $3^{\underline{a}}$ pessoa do plural constitui um processo de variação estável. A variante semivogal é estratificada por escolaridade, sendo mais produzida por falantes com nível mais baixo de escolaridade da amostra, isto é, com ensino fundamental, e a forma não marcada de $3^{\underline{a}}$ pessoa do singular com sujeito de $3^{\underline{a}}$ pessoa no plural tende a ser usada pelas mulheres.

O resultado observado para a variável sexo nos dados de $\mathrm{CV}$, não se enquadra no Princípio I de Labov (1990, p. 210-215), relativo ao comportamento de homens e mulheres em processos de variação estável, segundo o qual os homens tendem a usar variantes não padrão mais frequentemente que as mulheres. Para melhor situar esse resultado, foram realizados dois cruzamentos de grupos de fatores para os dados de concordância verbal: sexo e idade e sexo e escolaridade. Em ambas as rodadas, os dois grupos de fatores, formados pelo cruzamento das variáveis - sexo x escolaridade e sexo x idade, foram considerados significativos, isto é, foram selecionados pelo Goldvarb no step-up. Para o primeiro, os resultados apontaram que, independentemente da idade, as mulheres tendem a usar com mais frequência formas não marcadas de $3^{\underline{a}}$ pessoa, juntamente com os adolescentes do sexo masculino. Já nos resultados do cruzamento entre sexo e escolaridade, as mulheres, independentemente 
do nível de escolaridade, foram as que apresentaram tendência ao uso de formas não marcadas, juntamente com os homens com ensino fundamental. Por outro lado, a ausência de diferença entre homens e mulheres com relação à realização da semivogal também pode indicar graus não muito acentuados de estigma nessa variedade do PB associados às variáveis em questão. Esses resultados são indicativos de um padrão de avaliação social na comunidade de fala que precisa ser investigado com base em estudos de percepção e avaliação social dessas variantes.

Ainda, com vistas a situar o perfil de perda de características rurais para além das evidências quantitativas baseadas nos percentuais dos fatores das categorias macrossociais, os dados também foram observados em função de características específicas de cada uma das duas variáveis, bem como do comportamento de alguns indivíduos, quando pertinente. Com relação à concordância verbal de $3^{\underline{a}}$ pessoa, embora o percentual de ausência de concordância seja inferior ao percentual de usos com a forma verbal marcada, estando em consonância com percentuais obtidos em outros centros urbanos, como Rio de Janeiro e Florianópolis, mencionados na seção 2, foi observada uma alta incidência de formas não-marcadas com verbos da escala mais alta de saliência fônica (diferença entre a forma não marcada e a forma marcada envolve acréscimos de segmento, mudanças na raiz e formas supletivas, como veio/vieram, é/são), nas três faixas etárias estudadas, como em: Os filio é engraçado (informante mais jovem), Os minino era morto e vivo lá em casa (informante faixa etária intermediária), As casa era tampada de palha (informante mais velho). Embora não tenha sido objetivo do estudo a análise de variáveis linguísticas, para avançar a reflexão sobre o perfil sociolinguístico de Imperatriz, os dados foram agrupados e quantificados quanto a essa característica, e pôde ser observado o percentual de $37 \%$ de ausência de concordância em verbos do último nível de saliência. Esse percentual se aproxima dos $31 \%$ encontrados no estudo de Lucchesi et al. (2009) para esse fator, em dados de comunidades afro-brasileiras da Bahia com perfil rural, e está muito acima do 
percentual de $12 \%$ do estudo de Scherre e Naro (1996), a respeito dos dados da variedade urbana da cidade do Rio de Janeiro da Amostra Censo 1980. Assim, observase que, embora o percentual de ausência de concordância em Imperatriz se aproxime do observado em outros grandes centros, semelhante a Belo Horizonte, 34\%, por exemplo, como no estudo de Faria (2008), do ponto de vista qualitativo, esses casos indicam a presença de traços de ruralidade nessa localidade, ao mesmo tempo em que os percentuais de concordância são semelhantes aos encontrados em variedades urbanas.

Com relação à alternância entre consoante lateral (palatal e alveolar seguida de semivogal) e semivogal, além do baixo percentual de ocorrência da semivogal, não foi observado, na Amostra de Imperatriz, nenhum item lexical com frequência de realização da semivogal superior à realização como lateral. Itens frequentes no corpus, como filho, filha, mulher e trabalho, foram produzidos majoritariamente com a realização [lז $\mathrm{I}]$. Esse resultado é interessante porque indica um maior afastamento de característica rural na comunidade de fala de Imperatriz, mesmo entre falantes cujo percentual de uso da semivogal é alto. Foi observado que dois dos 18 falantes que compõem o presente corpus apresentam percentual de realização da semivogal acima do desvio padrão (Chi, 82\% - faixa etária mais velha, 62 anos, homem, ensino fundamental; Cil, $54 \%$ - faixa etária intermediária, homem, ensino fundamental) ${ }^{8}$. Entre os 6 falantes mais velhos, cujos dados foram considerados na análise estatística, há uma variabilidade muito grande com percentuais que vão de $3 \%$ a $82 \%$. Isso significa que o percentual geral de $27 \%$, obtido para essa faixa, não representa de fato uma baixa ocorrência da semivogal na comunidade, mas uma média de valores percentuais com extremos bastante distantes, que podem ter relação com o perfil social dos falantes, considerando outras características além das variáveis sexo e escolaridade. Entre os

\footnotetext{
${ }^{8}$ Um novo levantamento de outros três falantes da faixa dos mais velhos dos três níveis de escolaridade revelou percentual alto de semivogal somente no falante com ensino fundamental - Bai, 91,8\%.
} 
seis falantes da faixa etária mais jovem, quatro apresentaram percentual de realização da semivogal abaixo do percentual geral, $26 \%$, e dois, um pouco acima, mas muito próximos do percentual geral (Myl, 0\%; Deb, 2,7\%; Vin, 8,3\%; Clé, 15,7\%; Pau, 28,5\%, Luc, 30,7\%). Os percentuais observados para os mais jovens da amostra mostram a consolidação de uma variedade urbana de uma cidade populosa, e que se tornou polo comercial e educacional da região, levando à adoção de valores sociais de atribuição de um forte estigma à variante semivogal.

Por outro lado, esse resultado também pode estar relacionado ao contato dialetal entre falantes de diferentes localidades do Brasil, portanto, de diferentes variedades do PB, que contribuíram com suas características dialetais. De acordo com os dados apresentados no Quadro 2 do Anexo A, o segundo maior contingente populacional de migrantes em Imperatriz, a partir de 1991, é oriundo do Pará, considerando as informações dos Censos 1991 e 2000, muito embora não seja possível identificar, para esse conjunto de moradores de Imperatriz, a localidade de origem, no Pará. Porém, observam-se nos estudos realizados por Nunes (2006) e Soares (2008) em diversas localidades do Pará, e mencionados na seção 2, baixas taxas de ocorrência da semivogal, entre $1 \%$ e $18 \%$. As localidades se distribuem pelas seis mesorregiões do estado: Belém (Metropolitana de Belém), Soure (Marajó), Bragança (Nordeste Paraense), Santarém (Baixo Amazonas), Altamira (Sudoeste), Marabá, Curionópolis, Itupiranga, Dom Eliseu e Tucuruí (Sudeste). Em todas elas, o percentual de ocorrência da semivogal é muito baixo, o que significa uma realização categórica ou semicategórica, a depender do percentual encontrado. As localidades estudadas compreendem a capital do estado (Belém) e cidades de médio e pequeno porte (Soure, Curionópolis, Itupiranga e Dom Eliseu). Os estudos de Nunes (2006) e Soares (2008) apontam a predominância de uma articulação da consoante lateral seguida de semivogal que se situa na região pós-alveolar, sendo muito baixa a realização como lateral palatal $[\kappa]$. 
Uma vez que as faixas etárias da Amostra de Imperatriz foram estabelecidas de maneira a captar os ciclos econômicos e o fluxo migratório deles decorrente, observase que o período de aquisição da variedade local do conjunto de falantes da faixa etária mais nova coincide com o período em que os migrantes do Pará são o segundo maior contingente populacional da cidade de Imperatriz. É possível, portanto, que a variedade com realização semicategórica ou quase categórica da variante lateral seguida de semivogal, trazida pelos migrantes do Pará, conforme mencionado anteriormente, e a prevalência da variante semivogal entre migrantes oriundos de áreas rurais do interior do Maranhão tenham passado pela etapa de realocação, processo mencionado por Britain e Trudgill (1999, p. 247), na situação de contato dialetal de variedades mutuamente inteligíveis. Na realocação, variantes originalmente de variedades diferentes passam a alternar como variantes de uma mesma variável, assumindo novos valores estilísticos e sociais. A realização como lateral seguida de semivogal não é uma variante exclusiva nas localidades dos estudos sobre as diversas localidades do Pará, uma vez que alterna com a semivogal, não havendo, de fato, um caso de realocação. Porém, o maior contingente de migrantes dessas regiões fornece outra possibilidade fonética como modelo, contribuindo para impulsionar a variante lateral. Assim, os falantes mais novos avançam a implementação da variante lateral seguida de semivogal, não identificada como característica de fala rural, apresentando um comportamento uniforme de baixos percentuais de semivogal, independentemente da escolaridade.

\section{Considerações finais}

Este artigo apresentou os resultados de um estudo que buscou situar o perfil sociolinguístico da variedade urbana da cidade de Imperatriz, situada a Sudoeste do estado do Maranhão, localidade que, em um período de 50 anos, devido a mudanças na economia da região e o fluxo migratório decorrente, passou de comunidade rural a 
centro urbano, tornando-se, mais recentemente, referência como polo educacional e comercial da região. A dinâmica sociolinguística de Imperatriz foi observada considerando a distribuição das variantes de duas variáveis linguísticas estudadas alternância entre lateral palatal e semivogal e concordância verbal de $3^{\underline{a}}$ pessoa, em função das variáveis sociais estratificadoras da amostra. Do ponto de vista metodológico, a estratificação etária dos indivíduos da Amostra Imperatriz procurou capturar os ciclos econômicos, situando os falantes que adquiriram a variedade local em um período de maior isolamento de comunidade rural e os que adquiriram a variedade em dois diferentes momentos da emergência e consolidação da localidade como área urbana de referência no entorno geográfico, período com migração intensa, de cidadãos de todas as regiões brasileiras, mas preponderantemente de localidades do interior do Maranhão. Os resultados apontaram um decréscimo no uso de variantes associadas à fala rural (BORTONI-RICARDO, 1985), mas, por outro lado, a presença ainda de algumas características que têm sido observadas em comunidades rurais, como a maior incidência de ausência de concordância de $3^{\text {a }}$ pessoa do plural em certos tipos de verbos, como os que se situam no nível mais alto de saliência fônica (NARO, 1981). Atribuem-se também os baixos índices da variante semivogal à presença numerosa de migrantes do Pará, segundo maior contingente migratório para a localidade, na formação da variedade de Imperatriz, e cujas variedades de origem se caracterizam pela presença quase que categórica da variante lateral alveolar seguida de semivogal. Assim, os resultados apresentados mostraram os efeitos da urbanização intensa e do contato dialetal com um grupo específico de migrantes na configuração atual do perfil sociolinguístico da cidade de Imperatriz. 


\section{Referências Bibliográficas}

AGUILERA, V. de A. O papel da geolinguística no Brasil e a sua interface com a história da formação do português brasileiro. In: RAMOS, C. de M. de A. et al (org.). Pelos caminhos da dialetologia e da sociolinguística: entrelaçando saberes e vidas homenagem a Socorro Aragão. São Luís: EDUFMA, 2010. p. 69-90.

AMARAL, A. O dialeto caipira. 2. ed. São Paulo: HUCITEC/Secretaria da Cultura, Ciência e Tecnologia, 1976.

BORTONI-RICARDO, S. M. The urbanization of rural dialect speakers: a sociolinguistic study in Brazil. Cambridge: Cambridge University Press, 1985.

BORTONI-RICARDO, S. M. Contato de dialetos no Distrito Federal, Brasil. In: BORTONI-RICARDO, S. M.; VELLASCO, A. M. (org.). O falar candango. Brasília: Editora UNB, 2010. p. 17-32.

BRANDÃO, S. F. Um estudo variacionista sobre a lateral palatal. Letras de Hoje. Porto Alegre, v. 42, n. 3, p. 89-99, 2007. Disponível em: http://revistaseletronicas.pucrs.br/ojs/index.php/fale/issue/view/63. Acesso em: 28 maio 2012.

BRITAIN, D.; TRUDGILL, P. Migration, new-dialect formation and sociolinguistic refunctionalisation: reallocation as an outcome of dialect contact. Transactions of the Philological Society, v. 97, n. 2, p. 245-256, 1999. DOI https://doi.org/10.1111/1467968X.00050

CASTRO, E. F. Sobre o uso da semivogal [y] e a inserção da lateral palatal [ $\boldsymbol{\Lambda}$ ] no Português Brasileiro. 83 f. Dissertação (Mestrado em Estudos Linguísticos) Faculdade de Letras, Universidade Federal de Minas Gerais, Belo Horizonte, 2006.

CHAVES, L. M. do N.; MELO, F. E. S. de. A despalatalização de $/ K /$ na Zona Urbana de Rio Branco (AC). Cadernos do CNLF, v. 8, n. 4, p. 84-98, 2009. Disponível em: http://www.filologia.org.br/rph/ANO18/54SUP/013.pdf. Acesso em: 14 dez. 2014.

FARIA, N. V. M. de. A concordância verbal no português de Belo Horizonte. 119 f. Dissertação (Mestrado em Letras) - Faculdade de Letras, Pontifícia Universidade Católica de Minas Gerais, Belo Horizonte, 2008.

FERREIRA, M. M. A Variação da Lateral Palatal Segundo Transcrição do Banco de Dados VARSUL. 155 f. Dissertação (Mestrado em Letras) - Faculdade de Letras, Universidade Federal do Rio Grande do Sul, Porto Alegre, 2011. 
FRANKLIN, A. Breve história de Imperatriz. Imperatriz: Ética, 2005.

FRANKLIN, A. Apontamentos para a história econômica de Imperatriz. Imperatriz: Ética, 2008.

FREIRE, J. B. Variação da Lateral Palatal na Variedade e de Jacaraú (Paraíba). 111 f. Dissertação (Mestrado em Linguística) - Centro de Ciências Humanas, Letras e Artes, Universidade Federal da Paraíba, João Pessoa, 2011.

GOMES, C. A.; MELO, M. A. S. L.; BARCELLOS, M. E. M. Dinâmica da variação sociolinguística em contexto de exclusão social. Revista Virtual de Estudos da Linguagem, v. 14, p. 127-143, 2016.

GRACIOSA, D. Concordância verbal na fala culta carioca. 102 f. Dissertação (Mestrado em Letras Vernáculas). Faculdade de Letras, Universidade Federal do Rio Janeiro, Rio de Janeiro, 1991.

KERSWILL, P.; WILLIAMS, A. Creating a new town koine: children and language change in Milton Keynes. Language in Society, v. 29, n. 1, p. 65-115, 2000. DOI https://doi.org/10.1017/S0047404500001020

KERSWILL, P.; WILLIAMS, A. New towns and koineization: social linguistic and correlates. Linguistics, v. 43, n. 5, p. 1.023-1.048, 2005. DOI https://doi.org/10.1515/ling.2005.43.5.1023

LABOV, W. Sociolinguistic patterns. Philadelphia: University of Pennsylvania Press, 1972.

LABOV, W. The intersection of sex and social class in the course of linguistic change. Language Variation and Change, v. 2, p. 205-254, 1990. DOI https://doi.org/10.1017/S0954394500000338

LABOV, W. Principles of linguistic change: internal factors. Oxford: Blackwell, 1994.

LABOV, W. Principles of linguistic change: external factors. Cambridge: Blackwell, 2001, p. 572.

LUCCHESI, D.; BAXTER, A.; SILVA, J. A. A. da. A concordância verbal. In: LUCCHESI, D.; BAXTER, A.; RIBEIRO, I. (org.). O português afro-brasileiro. Bahia: EDUFBA, 2009. p. 331-371. DOI https://doi.org/10.7476/9788523208752 
MONGUILHOTT, I. de O. e S. Variação na concordância verbal de terceira pessoa em Florianópolis. 150 f. Dissertação (Mestrado em Linguística) - Faculdade de Letras, Universidade de Santa Catarina, Florianópolis, 2001.

NARO, A. J. The social and structural dimensions of a syntactic change. Language, v. 57, n. 1, p. 63-98, 1981. DOI https://doi.org/10.1353/lan.1981.0020

NUNES, C. F. Variações do Fonema / $\mathbf{N}$ no falar de quatro localidades do Sudoeste do Pará: uma descrição geo-sociolinguística. 177 f. Dissertação (Mestrado em Letras) Centro de Letras e Artes, Universidade Federal do Pará. Pós-Graduação em Letras. 2006.

OLIVEIRA, D.; MOTA, J. As variantes do fonema lateral palatal em inquéritos do Projeto Atlas Linguístico do Brasil (ALiB). In: III SEMINÁRIO DE PESQUISA EM ESTUDOS LINGÜÍSTICOS E III SEMINÁRIO DE PESQUISA EM ANÁLISE DO DISCURSO. Vitória da Conquista: UESB, 2007. v. 1. p. 205-209.

PINHEIRO, N. L. de A. O processo de variação das palatais lateral e nasal no português de Belo Horizonte. 142 f. Dissertação (Mestrado em Estudos Linguísticos) - Faculdade de Letras, Universidade Federal de Minas Gerais, Belo Horizonte, 2009.

QUANDT, V. O. A lateral palatal no português do Brasil e no português europeu. 215 f. Tese (Doutorado em Letras Vernáculas) - Faculdade de Letras, Universidade Federal do Rio de Janeiro, 2014.

SANKOFF, G. Linguistic Outcomes of Language Contact. In: CHAMBERS, J.; TRUDGILL, P.; SCHILLING-ESTES, N. (ed.). Handbook of Language Variation and Change. Oxford: $\quad$ Blackwell, 2002. p. 638-668. DOI https://doi.org/10.1111/b.9781405116923.2003.00034.x

SANTOS, K. B. Análise variacionista da vocalização da lateral palatal em PapagaiosMG. 76 f. Dissertação (Mestrado em Estudos Linguísticos) - Faculdade de Letras, Universidade Federal de Minas Gerais, Belo Horizonte, 2012.

SANTOS, J. M.; CHAVES, L. M. do N. Realização da Lateral Palatal $/ K /$ no Atlas Linguístico do Acre (ALIAC). Revista Philologus, n. 54, p. 142-159, 2012.

SCHERRE, M. M. P.; NARO, A. J. A concordância de número no português do Brasil: um caso típico de variação inerente. In: HORA, D. da (org.). Diversidade Linguística no Brasil. João Pessoa: Idéia, 1997. p. 93-114. 
SCHERRE, M. M. P.; NARO, A. J. Perceptual vs. Grammatical Constraints and Social Factors in Subject-Verb Agreement in Brazilian Portuguese. University of Pennsylvania, Working Papers in Linguistics, v. 16, p. 163-171, 2010.

SOARES, E. P. As palatais lateral e nasal no falar paraense: uma análise variacionista e fonológica. $184 \mathrm{f}$. Tese (Doutorado em Linguística), Centro de Humanidades, Universidade Federal do Ceará, Fortaleza, 2008.

TRUDGILL, P. J. Dialects in Contact. Oxford: Blackwell, 1986.

TRUDGILL, P. J. The chaos before the order: New Zealand English and the second stage of new dialect formation. In: JAHR, E. H. (ed.). Advances in Historical Sociolinguistics. Berlin: Mouton de Gruyter, 1998. p. 197-207.

VIEIRA, S. R. A não-concordância em dialetos populares: uma regra variável. Graphos, v. 2, n. 1, p. 115-133, 1997.

WILLIAMS, A.; KERSWILL, P. Dialect levelling: Continuity vs. change in Milton Keynes, Reading, and Hull. In: FOULKES, P.; DOCHERTY, G. (ed.). Urban Voices: accent studies in the British Isles. New York: Oxford University Press, 1999. p. 141162.

\section{ANEXOS}

ANEXO A - Dados Demográficos de Imperatriz - Censo e Origem de Migrantes.

Quadro 1 - Demografia de Imperatriz, MA.

\begin{tabular}{|l|l|l|l|l|l|}
\hline Ano & Total & Urbana & Rural & \multicolumn{3}{|l|}{ Residentes não naturais } \\
\hline & & & & Total & $\%$ \\
\hline 1940 & 9.331 & 1.002 & 8.329 & & \\
\hline 1950 & 14.064 & 1.630 & 12.434 & & \\
\hline 1960 & 39.169 & 8.987 & 30.182 & 30.969 & $79 \%$ \\
\hline 1970 & 80.827 & 46.117 & 34.710 & 52.403 & $65 \%$ \\
\hline 1980 & 220.095 & 111.705 & 108.390 & 93.007 & $42 \%$ \\
\hline 1991 & 276.502 & 210.051 & 66.451 & 88.550 & $32 \%$ \\
\hline 2000 & 230.566 & 218.673 & 11.893 & 11.589 & $5 \%$ \\
\hline 2010 & 247.505 & 234.547 & 12.958 & 13.589 & $5.4 \%$ \\
\hline
\end{tabular}

Fonte: IBGE e Franklin (2008).

Quadro 2 - Residentes não naturais do município chegados até 10 anos antes do Censo 


\begin{tabular}{|c|c|c|c|c|c|}
\hline UF & 1960 & 1970 & 1980 & 1991 & 2000 \\
\hline RO & 1 & 15 & 66 & 367 & 87 \\
\hline $\mathrm{AC}$ & 1 & 38 & 26 & 33 & 0 \\
\hline AM & 0 & 14 & 15 & 270 & 71 \\
\hline RR & 0 & 12 & 27 & 156 & 204 \\
\hline PA & 258 & 1.754 & 2.984 & 13.520 & 4.245 \\
\hline $\mathrm{AP}$ & 0 & 102 & 0 & 114 & 162 \\
\hline TO & - & - & - & 5.532 & 1.417 \\
\hline MA & 27.191 & 36.514 & 60.025 & 51.756 & $\mathrm{n} / \mathrm{c}$ \\
\hline PI & 1.290 & 3.148 & 4.460 & 3.906 & 904 \\
\hline CE & 721 & 1.614 & 3.959 & 1.576 & 326 \\
\hline RN & 20 & 72 & 330 & 329 & 95 \\
\hline PB & 92 & 375 & 692 & 358 & 85 \\
\hline PE & 209 & 548 & 1.138 & 1.231 & 173 \\
\hline $\mathrm{AL}$ & 6 & 9 & 153 & 160 & 94 \\
\hline SE & 0 & 114 & 133 & 145 & 18 \\
\hline BA & 4 & 1.830 & 4.565 & 854 & 253 \\
\hline MG & 5 & 1.832 & 3.843 & 1.219 & 583 \\
\hline ES & 10 & 827 & 1.116 & 289 & 111 \\
\hline RJ & 0 & 41 & 159 & 614 & 123 \\
\hline GB & 2 & 8 & -- & - & - \\
\hline SP & 17 & 186 & 878 & 1.583 & 933 \\
\hline PR & 17 & 108 & 369 & 244 & 68 \\
\hline SC & 0 & 4 & 90 & 33 & 51 \\
\hline RS & 7 & 4 & 120 & 77 & 177 \\
\hline MS & - & - & 37 & 44 & 105 \\
\hline MT & 17 & 102 & 167 & 632 & 295 \\
\hline GO & 876 & 2.904 & 7.077 & 1.981 & 481 \\
\hline DF & 0 & 112 & 404 & 1.335 & 358 \\
\hline $\mathrm{N} / \mathrm{D}$ & 23 & 112 & 200 & 125 & 95 \\
\hline Exterior & 1 & 4 & 44 & 67 & 70 \\
\hline
\end{tabular}

Fonte: IBGE e Franklin (2008). 